\title{
Determining Relative Microsatellite Allele Frequencies in Pooled DNA Samples
}

\author{
H. Khatib, ${ }^{1}$ A. Darvasi, Y. Plotski, ${ }^{1}$ and M. Soller
}

Department of Genetics, The Hebrew University of Jerusalem, 91904 Jerusalem, Israel

\begin{abstract}
Accurate quantification of relative allele frequencies in pooled DNA samples can be carried out for microsatellite markers having a dinucleotide repeat unit, conditional on the absence of overlapping "shadow" bands. This provides a basis for extending DNA pooling to this useful class of DNA marker. Expressions for the standard error of densitometric estimates of allele frequencies from pooled samples are presented, and their statistical application is illustrated in a variety of situations. This enables DNA pooling to be utilized in situations requiring the testing of statistical hypotheses concerning differences in allele frequencies between populations, or samples.
\end{abstract}

A number of studies have shown that the relative density of polymorphic bands obtained on Southern analysis of pooled DNA samples stands in approximate relation to relative allele frequency as determined by separate genotyping of each of the individuals making up the pool. ${ }^{(1-8)}$ With the introduction of microsatellite markers uncovered by PCR methodologies, the DNA pooling technique has been extended to this class of polymorphism as well, and recent work, with a pair of microsatellite markers having tetranucleotide and dodecanucleotide repeat units, respectively, has shown that densitometric determination of microsatellite allele frequencies from pooled DNA samples was close to that obtained by individual genotyping. ${ }^{(9)}$

The DNA pooling procedure has been found useful in studies aimed at comparison of allelic frequencies in different populations, or at determination of linkage between marker loci and quantitative trait loci (QTL). However, procedures for statistical analysis of allele frequencies obtained in this manner have not hitherto been available. Consequently, results obtained by densitometry of pooled DNA samples are treated as preliminary or indicative but not as a means of drawing statistically valid conclusions in their own right. The primary objective of the present study, therefore, was to develop an expression for the standard error of densitometric estimates of microsatellite marker allele frequencies from pooled samples and apply this to a variety of situations, illustrating the circumstances within which statistically valid conclusions can be drawn from such results. Although framed in terms of microsatellite markers, the approach developed is equally valid for any class of marker for which allele frequen- cies can be determined by densitometry of pooled DNA samples.

In addition, because microsatellite markers having a dinucleotide repeat unit are used very commonly in genetic analyses, the present study was intended to specifically explore the utility of this class of marker for DNA pooling. It was found that the relative frequency of microsatellite alleles for this class of marker in pooled DNA samples could be estimated accurately by densitometry; this is conditional, however, on the absence of prominent overlapping shadow bands (i.e., artifactual amplification products one or two repeat units smaller in size than the actual allele).

\section{MATERIALS AND METHODS}

\section{Source of DNA Samples}

All DNA samples were obtained from chickens deriving from a resource population maintained at North Talpiot Experimental Farm of the Hebrew University of Jerusalem. This population was founded by crossing a single white rock broiler breed male (of Arbor Acre origin) with five females of the line-O semi-inbred white leghorn line (developed at Avian Disease and Oncology Laboratory, East Lansing, MI). The $\mathrm{F}_{1}$ birds were recurrently intercrossed up to the $F_{5}$ generation and phenotyped with respect to a number of quantitative traits. Blood samples were obtained from each bird.

\section{Experimental Design}

To explore the potential of DNA pooling, three experiments were carried out. Except where stated otherwise, each pool was prepared in duplicate and each duplicate pool was amplified in duplicate. 
Microsatellites used in each experiment are listed in Table 1.

\section{Two-sample Pools}

Two individuals, both from the $\mathrm{F}_{3}$ generation, were identified as being homozygous for alternative alleles at the microsatellite 30-1 locus. DNA samples were obtained from each individual and pooled in defined proportions ( 0.90 : $0.10,0.75: 0.25,0.60: 0.40,0.55: 0.45,0.50$ : $0.50,0.45: 0.55,0.40: 0.60,0.25: 0.75,0.10$ : $0.90)$. A similar procedure was carried out with DNA samples of two other individuals, respectively, that were homozygous for alternative alleles at the microsatellite $\alpha$-smooth muscle actin (ASMA) locus.

\section{Multisample Pools}

Four pools were constructed for microsatellite MCW5, by choosing 6-7 individuals out of a panel of 16 individuals of the F1 generation. Five alleles were present; two were derived from the male founder parent (heterozygous for this marker). These alleles were also shared by the female founder parents. Two additional alleles were found among the females only. The polymorphic nature of the females was consistent with their semi-inbred nature. A fifth allele at this locus apparently arose by mutation during the course of the experiment. The individuals in each pool were chosen so as to create slightly different allele frequencies in the different pools. Equal amounts of DNA were sampled from each bird in the pool, but in some instances a double sample was taken from a single individual to achieve a particular allele frequency in the pool. Three pools were constructed for microsatellite 4-1, in the same manner, by choosing 8 out of a panel of 12 individuals of the $F_{3}$ generation. In this case, only two alleles were present: one derived from the male founder and the other from the female founders.

\section{Selective Genotyping with DNA Pooling}

All individuals of the $F_{2}$ and $F_{3}$ generations were evaluated for body weight at 14 weeks of age. On the basis of the individual body weights, four groups were formed in each generation, comprising the 10 heaviest and the 10 lightest males and the 10 heaviest and the 10 lightest females. Each chosen individual was genotyped with respect to a panel of 21 microsatellites markers. For some of the microsatellite markers, allele frequencies in the "heavy" and "light" groups differed; for others, such differences were not found. Representative groups of both sorts were chosen for pooling (Table 1).

\section{DNA Extraction}

Blood samples were resuspended in anticoagulation solution (0.5\% EDTA at $\mathrm{pH}$ 8.0, final concentration) and stored at $-20^{\circ} \mathrm{C}$. DNA was extracted from $50-\mu \mathrm{l}$ blood samples using standard phenolchloroform (1:1), proteinase $\mathrm{K}$ extraction procedures. ${ }^{(11)}$ Following extraction, DNA was stored at $4^{\circ} \mathrm{C}$ in TrisEDTA buffer. DNA concentration and purity were determined spectrophotometrically.

\section{Microsatellites}

Table 1 gives designation, reference source, number of alleles, and product length for each of the microsatellite markers used in this study. Primer sequences are detailed in the references. As is well known, some dinucleotide microsatellites show prominent shadow bands consisting of artifactual amplification products one or two repeat units smaller in size than the actual allele. When shade bands of the longer alleles overlap main bands of the shorter alleles, densitometric estimates of allele frequencies in pooled DNA samples do not correspond to the actual allele frequencies. Consistently, this study included only microsatellites that did not show prominent overlapping shadow bands in the samples examined.

\section{Genotyping of Individual or Pooled DNA Samples}

\section{Pooled Amplification}

The reaction mixture comprised the following: primers each at $0.5 \mu \mathrm{M}$, dNTP each at $190 \mu \mathrm{M}, 1.0$ unit of Taq polymerase (Promega)/25- $\mu$ l reaction mixture, $\sim 50 \mathrm{ng}$ of template genomic DNA (prepared from red blood cells) in each $25-\mu l$ reaction mixture, $10 \mathrm{~mm}$ Tris- $\mathrm{HCl}$ (pH 8.3), $50 \mathrm{~mm} \mathrm{KCl}, 1.5 \mathrm{~mm} \mathrm{MgCl}_{2}$, $0.01 \%$ (wt/vol) gelatin. The temperature cycling was as follows: Denaturing was at $95^{\circ} \mathrm{C}$ for $60 \mathrm{sec}$; annealing was for $60 \mathrm{sec}$ at $55^{\circ} \mathrm{C}$ or $60^{\circ} \mathrm{C}$, depending on primer composition; extension was at $72^{\circ} \mathrm{C}$ for $30 \mathrm{sec}$; the reaction was carried out for 30 cycles, and the final extension was at $72^{\circ} \mathrm{C}$ for $10 \mathrm{~min}$.

\section{Labeled PCR Amplification}

The amplification product was labeled by ${ }^{35}$ S-end-labeling of one primer. The primer was end-labeled in a reaction mixture containing $1 \mu \mathrm{g}$ of primer, $2 \mu \mathrm{l}$ of $10 \times$ kinase buffer (U.S. Biochemical), $2 \mu \mathrm{l}$ of spermidine $(10 \mathrm{~mm}), 7 \mu \mathrm{l}$ of $\gamma^{-{ }^{35} \mathrm{~S}}$ labeled ATP, 10 units of T4 DNA kinase (U.S. Biochemical), and water to $20 \mu \mathrm{l}$. The reaction mixture was incubated at $37^{\circ} \mathrm{C}$ for $1 \mathrm{hr}$. The reaction was terminated by heating to $100^{\circ} \mathrm{C}$ for $2 \mathrm{~min}$.

For labeled PCR amplification, the reaction mixture contained $0.5 \mu$ l of labeled primer reaction mixture plus 0.75 $\mu \mathrm{l}$ of unlabeled primer $(0.5 \mu \mathrm{M}$ total primer), and $1.25 \mu \mathrm{l}$ of the other, unlabeled primer $(0.5 \mu \mathrm{M}$ total primer $)$. All 
other components and cycling were as in the unlabeled PCR amplification.

In some instances, for which microsatellite alleles differed widely in length, $5 \mu \mathrm{l}$ of the amplification reaction mixture was run in a $2 \%$ agarose minigel and microsatellite alleles were determined directly on the minigel.

\section{Denaturing Polyacrylamide Gel Electrophoresis of PCR Products}

In most instances, to examine the reaction products for polymorphism length, $3.5 \mu \mathrm{l}$ of reaction product was subjected to denaturing polyacrylamide gel electrophoresis in a sequencing gel apparatus (Bio-Rad). The $6 \%$ acrylamide gel was prepared according to Maniatis et al. ${ }^{(11)}$ The gel was run at $2000 \mathrm{~V}$, adjusted as needed to maintain the desired temperature range $\left(50-55^{\circ} \mathrm{C}\right)$. The length of the run varied from 1.5 to $3 \mathrm{hr}$, depending on product size. The gel was then dried for $1.5 \mathrm{hr}$ in a gel dryer (Bio-Rad). Autoradiography was carried out at room temperature for 1-3 days.

\section{Pooling of DNA Samples}

Maximum accuracy in determination of DNA concentration in the individual samples making up the pool is critical for effective pooling. Our procedure was as follows: After initial determination of DNA concentration in the DNA sample following extraction, an aliquot was taken and diluted in water to give a calculated concentration of $50 \mathrm{ng} / \mu \mathrm{l}$. The actual concentration was then determined by spectrophotometer. Note: All concentrations for a given pool were determined during the same session at the spectrophotometer. When DNA concentration was $>50 \mathrm{ng} / \mu \mathrm{l}$, it was convenient to dilute to a final concentration of 50 $\mathrm{ng} / \mu \mathrm{l}$. When DNA concentration was $<50 \mathrm{ng} / \mu \mathrm{l}$, the size of the aliquot taken for pooling was adjusted accordingly. In both cases aliquot size was such as to give a total quantity of $1 \mu \mathrm{g}$ of DNA for each individual in the pool. The same procedure was followed irrespective of the number of individuals in the pool. For the two-sample pools, DNA of the two individuals making up the pool was prepared at a concentration of $50 \mathrm{ng} / \mu \mathrm{l}$. The pool was then prepared using appropriate aliquots of each of the two individuals, to a total volume of $100 \mu \mathrm{l}$.

\section{Densitometry of Autoradiographs and of Negative Polaroid Films}

Quantitative estimation of relative band areas was obtained by densitometry of autoradiographs or Polaroid negatives using a scanning densitometer (model SL-TRFF, Biomed Instruments). Films for autoradiography were not pre-flashed, as we have found that the increased sensitivity is not necessary for analysis of PCR products. Exposure times were adjusted so that band intensities of the autoradiographs remained with the linear range. In current work in our laboratory with the DNA pooling technique, we use a PhosphorImager, which has a much greater linear range, with similar overall results.

When alleles were well separated, without prominent shadow bands, the software associated with the densitometer provided quantitative estimates of relative band area, corresponding to each allele. However, when there were prominent shadow bands, the densitometer provided quantitative estimates of the areas under each peak, but only representative peaks were taken for each allele. In this case, relative band density was calculated as the area of the representative peak, divided by the total area of all representative peaks.

\section{Statistical Analyses}

The standard deviation between replicate amplifications of the same pool was calculated by standard methods. The overall standard deviation was obtained by squaring the individual standard deviations and taking the square root of the mean square. This was taken as an estimate of technical error of amplification and densitometry, denoted $s_{\mathrm{A}}$.
The standard deviation between individual amplifications of replicate pools, denoted $s_{\mathrm{R}}$, was obtained by calculating the standard deviation of all possible pairs of values of individual amplifications of one pool with individual amplifications of the other pool. The standard deviation due to technical error in making up the pools, denoted $s_{\mathbf{p}}$, was then obtained as $s_{\mathrm{P}}=\left(s_{\mathrm{R}}{ }^{2}-s_{\mathrm{A}}{ }^{2}\right)^{0.5}$.

The standard error S.E.) for estimates based on $m$ replicate amplifications of $k$ replicated pools, was then calculated as $\left(s_{\mathrm{P}}^{2} / k+s_{\mathrm{A}}^{2} / m k\right)^{0.5}$. The standard error for differences between two pools assumed to exactly represent their respective populations (s.E.D.) will then equal $2^{0.5}$ s.E., and the least significant difference (L.S.D.) between two such samples (twotail test) will equal $z_{1-\alpha / 2}$ S.E.D., where $\alpha$ is the level of significance and $z$ is the standardized normal variable for which the area under the standardized normal curve is equal to $1-\alpha / 2$.

When a pool represents a sample from its respective populations, binomial sampling variation will also contribute to the standard error. In this case, the standard error associated with an allele frequency estimate of a single sample from the population will equal $\left[p(1-p) / 2 n+s_{\mathrm{p}}{ }^{2} / k+s_{\mathrm{A}}{ }^{2} / m k\right]^{0.5}$, where $p$ is the allelic frequency in the population, $n$ is the number of individuals sampled, and other symbols are as above. The S.E.D. and L.S.D. are calculated as above, assuming $p=0.5$.

\section{RESULTS}

Figure 1 illustrates quantitative DNA amplification for the two-sample pools of microsatellite $30-1$. Note the prominent, but nonoverlapping, shadow bands. Ta-

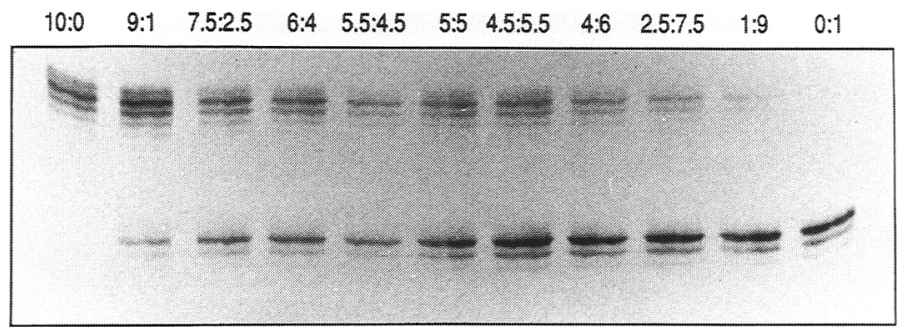

FIGURE 1 Two-sample pools for microsatellite 30-1. DNAs from individuals homozygous for alternative alleles at this locus were pooled in defined proportions as shown at the top. Duplicate amplifications are in adjoining lanes at each proportion. The amplification product was endlabeled and subjected to denaturing polyacrylamide gel electrophoresis in a sequencing gel apparatus. Quantitative estimation of relative band areas was obtained by densitometry of the autoradiograph. 
bles 2,3 , and 4 give the actual allele proportions in the pools and the relative allele frequencies as obtained by densitometry for two-sample pools, multisample pools, and selective genotyping pools, respectively. In all cases, there was a clear monotonic correlation between actual allele proportions in the pools and allele proportions as determined by densitometry, with very few rank reversals. As shown in Tables 2-4, alleles present in the pooled sample at a frequency of 0.10 were readily detected and their frequency was accurately estimated.

Pooled over all experiments and microsatellites, the average standard deviation between replicate amplifications of the same pool $\left(s_{\mathrm{A}}\right)$ was 0.025 . Pooled over all experiments and microsatellites, the average standard deviation between single amplifications of replicate pools $\left(s_{\mathrm{R}}\right)$ was 0.044 . Technical error in making up the pools $\left(s_{\mathrm{P}}\right)$ can now be calculated (see Materials and Methods) and is equal to 0.036 . Thus, there is a real difference in results from replicate pools of the same individuals over and above the differences that would be obtained by replicate amplifications from the same pool.

TABLE 2 Two-sample Pools of Alternative Homozygotes for Microsatellite Markers 30-1 and ASMA, Showing Actual Allele Proportions in the Pools and Allele Proportions as Estimated by Densitometry

\begin{tabular}{|c|c|c|c|c|c|c|c|c|}
\hline \multirow{2}{*}{$\begin{array}{l}\text { Actual } \\
\text { proportion }\end{array}$} & \multicolumn{5}{|c|}{ Microsatellite 30-1 } & \multicolumn{3}{|c|}{ Microsatellite ASMA } \\
\hline & pool & $\mathrm{R}-1$ & $\mathrm{R}-2$ & M1 & M2 & $\mathrm{R}-1$ & $\mathrm{R}-2$ & M1 \\
\hline \multirow[t]{2}{*}{0.90} & 1 & 0.81 & 0.73 & 0.77 & & 0.98 & 0.98 & 0.98 \\
\hline & 2 & 0.86 & 0.82 & 0.84 & 0.81 & & & \\
\hline \multirow[t]{2}{*}{0.75} & 1 & 0.50 & 0.50 & 0.50 & & 0.92 & 0.92 & 0.92 \\
\hline & 2 & 0.56 & 0.53 & 0.55 & 0.52 & & & \\
\hline \multirow[t]{2}{*}{0.60} & 1 & 0.38 & 0.40 & 0.39 & & 0.83 & 0.83 & 0.83 \\
\hline & 2 & 0.52 & 0.57 & 0.55 & 0.47 & & & \\
\hline \multirow[t]{2}{*}{0.55} & 1 & 0.40 & 0.37 & 0.39 & & 0.83 & 0.80 & 0.82 \\
\hline & 2 & 0.53 & 0.40 & 0.47 & 0.43 & & & \\
\hline \multirow[t]{2}{*}{0.50} & 1 & 0.30 & 0.28 & 0.29 & & 0.79 & 0.79 & 0.79 \\
\hline & 2 & 0.31 & 0.32 & 0.32 & 0.30 & . & & \\
\hline \multirow[t]{2}{*}{0.45} & 1 & 0.27 & 0.27 & 0.27 & & 0.69 & 0.73 & 0.71 \\
\hline & 2 & 0.27 & 0.26 & 0.27 & 0.27 & & & \\
\hline \multirow[t]{2}{*}{0.40} & 1 & 0.30 & 0.25 & 0.28 & & 0.73 & 0.67 & 0.70 \\
\hline & 2 & 0.18 & 0.18 & 0.18 & 0.23 & & & \\
\hline \multirow[t]{2}{*}{0.25} & 1 & 0.18 & 0.16 & 0.17 & & 0.49 & 0.49 & 0.49 \\
\hline & 2 & 0.10 & 0.10 & 0.10 & 0.14 & & & \\
\hline \multirow[t]{2}{*}{0.10} & 1 & 0.06 & 0.07 & 0.07 & & 0.32 & 0.37 & 0.35 \\
\hline & 2 & 0.09 & 0.07 & 0.08 & 0.07 & & & \\
\hline
\end{tabular}

For 30-1, each constructed proportion was made up in duplicate pools $(1,2)$ and each pool was amplified in duplicate (R-1, R-2). For ASMA, each pool was made up once only and amplified in duplicate. Means for replicate amplifications are shown separately for each pool (M1) and combined for both pools (M2). Estimated by Densitometry both pools (M2).
On the basis of the above two sources of technical error, the L.S.D. $(\alpha=0.05)$ for comparisons of densitometry values based on various combinations of repli-

TABLE 3 Multisample Pools for Microsatellite Markers MCW5 and 4-1, Showing Actual Allele Proportions in the Pools (in Parentheses) and Allele Proportions as

\begin{tabular}{|c|c|c|c|c|c|c|c|c|c|c|}
\hline \multicolumn{5}{|c|}{ Microsatellite MCW5 } & \multicolumn{6}{|c|}{ Microsatellite 4-1 (allele S1) } \\
\hline$\overline{\operatorname{mix}}$ & allele & R-1 & $\mathrm{R}-2$ & $\bar{M}$ & $\operatorname{mix}$ & pool & R-1 & $\mathrm{R}-2$ & $\mathbf{M}$ & $\mathrm{M}$ \\
\hline \multirow[t]{2}{*}{1} & SD1 $(0.50)$ & 0.58 & 0.58 & 0.58 & $1(0.44)$ & 1 & 0.42 & 0.40 & 0.41 & \\
\hline & & & & & & 2 & 0.39 & 0.42 & 0.41 & 0.41 \\
\hline \multirow[t]{5}{*}{2} & SD1 (0.42) & 0.44 & 0.47 & 0.46 & & & & & & \\
\hline & SD2 (0.08) & 0.09 & 0.10 & 0.10 & $2(0.56)$ & 1 & 0.59 & 0.56 & 0.58 & \\
\hline & D3 (0.08) & 0.07 & 0.08 & 0.08 & & 2 & 0.58 & 0.60 & 0.59 & 0.58 \\
\hline & D4 $\quad(0.42)$ & 0.39 & 0.35 & 0.37 & & & & & & \\
\hline & & & & & $3(0.69)$ & 1 & 0.71 & 0.72 & 0.72 & \\
\hline \multirow[t]{5}{*}{3} & SD1 (0.33) & 0.39 & 0.37 & 0.38 & & 2 & 0.72 & 0.72 & 0.72 & 0.72 \\
\hline & SD2 (0.17) & 0.19 & 0.22 & 0.21 & & & & & & \\
\hline & D3 $(0.17)$ & 0.09 & 0.08 & 0.09 & & & & & & \\
\hline & D4 (0.33) & 0.31 & 0.23 & 0.27 & & & & & & \\
\hline & new $(0.08)$ & 0.09 & 0.09 & 0.09 & & & & & & \\
\hline \multirow[t]{4}{*}{4} & SD1 (0.34) & 0.24 & 0.22 & 0.23 & & & & & & \\
\hline & SD2 (0.13) & 0.26 & 0.33 & 0.30 & & & & & & \\
\hline & D3 $(0.19)$ & 0.27 & 0.25 & 0.26 & & & & & & \\
\hline & D4 $\quad(0.34)$ & 0.23 & 0.18 & 0.21 & & & & & & \\
\hline
\end{tabular}

Each constructed proportion (mix-1, mix-2, etc.) was made up as single (microsatellite MCW5) or duplicate (microsatellite 4-1) pools $(1,2)$, and each pool was amplified in duplicate (R1, R2). Means for replicate amplifications are shown separately for each pool (M1) and combined for 
TABLE 4 Selective Genotyping Pools for Microsatellite Markers VITC, GGY, 4-1, and 2-1A Showing Actual Allele Proportions in the Pools and Allele Proportions as Estimated by Densitometry

\begin{tabular}{|c|c|c|c|c|c|c|}
\hline Microsatellite & Group & Pool & $\mathrm{R}-1$ & $\mathrm{R}-2$ & M1 & M2 \\
\hline \multirow[t]{6}{*}{ VITC (SD1) } & $\mathrm{F}_{3}, \mathrm{FH}(0.75)$ & 1 & 0.71 & & & \\
\hline & & 2 & 0.73 & & & 0.72 \\
\hline & $\mathrm{F}_{3}, \mathrm{FL}(0.11)$ & 1 & 0.09 & & & \\
\hline & & 2 & 0.10 & & & 0.10 \\
\hline & $\mathrm{F}_{3}, \mathrm{MH}(0.50)$ & 1 & 0.43 & 0.48 & 0.46 & \\
\hline & & 2 & 0.50 & 0.54 & 0.52 & 0.49 \\
\hline \multirow[t]{4}{*}{ GGY (S1) } & $\mathrm{F}_{3 \mathrm{~b}} \mathrm{MH}(0.70)$ & 1 & 0.73 & 0.70 & 0.72 & \\
\hline & & 2 & 0.72 & 0.72 & 0.72 & 0.72 \\
\hline & $\mathrm{F}_{3}, \mathrm{ML}(0.44)$ & 1 & 0.41 & 0.43 & 0.42 & \\
\hline & & 2 & 0.45 & 0.48 & 0.46 & 0.44 \\
\hline \multirow[t]{4}{*}{ 4-1 (S1) } & $\mathrm{F}_{3}, \mathrm{FH}(0.45)$ & 1 & 0.43 & 0.46 & 0.45 & \\
\hline & & 2 & 0.46 & 0.46 & 0.46 & 0.45 \\
\hline & $\mathrm{F}_{3}, \mathrm{FL}(0.45)$ & 1 & 0.48 & 0.48 & 0.48 & \\
\hline & & 2 & 0.43 & 0.42 & 0.43 & 0.45 \\
\hline \multirow[t]{4}{*}{ 2-1A (S1) } & $\mathrm{F}_{3}, \mathrm{MH}(0.55)$ & 1 & 0.56 & 0.58 & 0.57 & \\
\hline & & 2 & 0.52 & 0.55 & 0.53 & 0.55 \\
\hline & $\mathrm{F}_{3}, \mathrm{ML}(0.50)$ & 1 & 0.52 & 0.53 & 0.53 & \\
\hline & & 2 & 0.54 & 0.45 & 0.50 & 0.51 \\
\hline
\end{tabular}

Each pool was made up in duplicate $(1,2)$, and each pool was amplified in duplicate (R1, R2), except for microsatellite VITC. Means for replicate amplifications are shown separately for each pool (M1) and combined for both pools (M2). Selective genotyping groups: $\left(F_{3}\right) F_{3}$ generation; (M) males; (F) females; $(\mathrm{H})$ high trait value group; $(\mathrm{L})$ low trait value group.
When sample values are taken to represent population values, the L.S.D.s also include a major component because of binomial sampling from the population value. In this case, power for distinguishing two populations on the basis of the samples depends very much on the number of individuals in the samples. When the number of individuals is small $(n=10)$, binomial error is the main source of error, and the L.S.D. for pooled samples is not much greater than that for individual genotyping and is not much affected by replication. When the number of individuals in the sample is large ( $n=100$ or $n=200$ ), however, technical error will increase L.S.D. by $10-100 \%$, depending on the degree of replication. In these cases, replication of pools can reduce L.S.D. considerably. Because DNA pooling can allow much greater samples to be studied, the de-
TABLE 5 L.S.D.s for Comparisons of Allelic Frequencies Obtained by Densitometry of Pooled DNA Samples

\begin{tabular}{|c|c|c|c|c|c|c|c|c|c|}
\hline & \multicolumn{3}{|c|}{$m=1$} & \multicolumn{3}{|c|}{$m=2$} & \multicolumn{3}{|c|}{$m=4$} \\
\hline & $k=1$ & $k=2$ & $k=4$ & $k=1$ & $k=2$ & $k=4$ & $k=1$ & $k=2$ & $k=4$ \\
\hline \multicolumn{10}{|c|}{ L.S.D. between samples ${ }^{\mathrm{a}}$} \\
\hline & 0.121 & 0.111 & 0.106 & 0.086 & 0.079 & 0.075 & 0.061 & 0.056 & 0.053 \\
\hline \multicolumn{10}{|c|}{ L.S.D. between populations ${ }^{b}$} \\
\hline $\begin{array}{l}n=10 \\
(0.310)\end{array}$ & 0.333 & 0.329 & 0.327 & 0.322 & 0.320 & 0.319 & 0.316 & 0.315 & 0.314 \\
\hline $\begin{array}{l}n=100 \\
(0.098)\end{array}$ & 0.156 & 0.148 & 0.144 & 0.130 & 0.126 & 0.123 & 0.115 & 0.113 & 0.111 \\
\hline $\begin{array}{l}n=200 \\
(0.069)\end{array}$ & 0.140 & 0.131 & 0.126 & 0.110 & 0.105 & 0.102 & 0.092 & 0.089 & 0.087 \\
\hline
\end{tabular}

${ }^{a}$ L.S.D.s given as a function of the number of replicate pools $(m)$ per sample, number of replicate amplifications per pool $(k)$, and number of individuals per sample $(n)$.

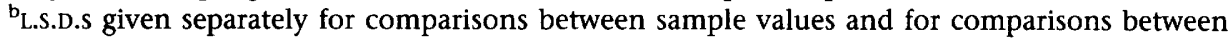
populations based on samples. In parentheses below " $n$ " values is the L.S.D. for individual genotyping with the given sample number. (See text for further details.) crease in binomial sampling error obtained by the larger sample can more than offset the contribution of technical error. Thus, the L.S.D. for a DNA pool from a sample of 100 , and single replication, is half that for individual genotyping of a sample of 10 . Similarly, the L.S.D. for a DNA pool from a sample of 200 with four replicates of the pool is less than that of the L.S.D. for individual genotyping of a sample of 100; yet this is achieved at a 25 -fold reduction in genotyping.

\section{DISCUSSION}

The results of this study show that densitometry of PCR amplifications from pooled DNA samples can successfully identify differences in allele frequencies between samples. Statistical power is excellent when the differences in allele frequency are large ( 0.20 or greater), but significant differences are rarely obtained when differences in allele frequency are small ( 0.10 or less). Thus, this study shows that densitometry of pooled DNA samples can serve as an effective preliminary screen for marker differences between samples, rapidly eliminating those markers that are not differentialy distributed, without delivering too many false positives. Those markers that show consistent differences in densitometry of pooled DNA samples can then be examined on an individual basis to establish sample and population differences more firmly.

We have considered the use of DNA pooling samples as a means of obtaining estimates of differences in allele frequencies between samples. This avoids the problem of differential allele amplification. However, if differential allele amplification is absent, or well characterized, then DNA pooling can also be used to obtain estimates of absolute allele frequencies in a sample, with standard error as described in Materials and Methods.

When samples are used to derive conclusions about populations from which they were drawn, DNA pooling can increase power, by allowing larger sample numbers to be examined. In this case, it should be noted that obtaining the samples and producing replicate pools is a one-time investment. If the pools are then examined for many markers, the saving in genotyping costs as compared with individual genotyping will be very 
great. This is exactly the situation encountered in selective genotyping for determination of linkage between marker loci and quantitative trait loci based on selective genotyping. ${ }^{(12-14)}$ DNA pooling holds much promise for markedly reducing genotyping costs for this application. A detailed treatment of the statistics of selective genotyping with DNA pooling is, however, beyond the scope of this study and will be presented elsewhere.

\section{ACKNOWLEDGMENTS}

This research was supported by a grant from the Israel Ministry of Science and Technology (MOST) and the Bundesministerium fuer Forschung und Technologie (BMFT).

\section{REFERENCES}

1. Dunnington, E.A., O. Gal, Y. Plotsky, A. Haberfeld, T. Kirk, A. Goldberg, U. Lavi, A. Cahaner, P.B. Siegel, and J. Hillel. 1990. DNA fingerprints of chickens selected for high and low body weight for 31 generations. Anim. Genet. 21: 221-231.

2. Dunnington, E.A., O. Gal, P.B. Siegel, A. Haberfeld, A. Cahaner, U. Lavi, Y. Plotsky, and J. Hillel. 1991. Deoxyribonucleic acid fingerprint comparisons bewteen selected populations of chickens. Poultry Sci. 70: 463-467.

3. Dunnington, E.A., A. Haberfeld, L.C. Stallard, P.B. Siegel, and J. Hillel. 1992. Deoxyribonucleic acid fingerprint bands linked to loci coding for quantitative traits in chickens. Poultry Sci. 71: 12511258.

4. Hillel, J., R. Avner, C. Baxter-Jones, E.A. Dunnington, A. Cahaner, and P.B. Siegel. 1990. DNA fingerprints from blood mixes in chickens and turkeys. Anim. Biotechnol. 1: 201-204.

5. Hillel, J., O. Gal, P.B. Siegel, and E.A. Dunnington. 1991. Line-specific DNA finger print bands in lines of chickens selected for high or low antibody response to sheep erythrocytes. Arch. Gefluegelk. 53: 189-191.

6. Hillel, J., D. Kalay, O. Gal, P. Weisberger, Y. Plotsky, and A. Haberfeld. 1993. Applications of multilocus molecular markers in cattle breeding: 2 . Use of blood mixes. J. Dairy Sci. 76: 653-657.

7. Sabour, M.P., J.R. Chambers, A.A. Grunder, U. Kuhnlein, and J.S. Gavora. 1992. Endogenous viral gene distribution in populations of meat-type chickens. Poultry Sci. 71: 1259-1270.

8. Plotsky, Y., A. Cahaner, A. Haberfeld, U. Lavi, S.J. Lamont, and J. Hillel. 1993. DNA fingerprint bands applied to linkage anal- ysis with quantitative trait loci in chickens. Anim. Genet. 24: 105-110.5.

9. Pacek, P., A. Sajantila, and A.-C. Syvanen. 1993. Determination of allele frequencies at loci with length polymorphism by quantitative analysis of DNA amplified from pooled samples. PCR Methods Applic. 2: 313-317.

10. Khatib, H., E. Genislav, L.B. Crittenden, N. Bumstead, and M. Soller. 1993. Sequence tagged microsatellite sites as markers in chicken reference and resource populations. Animal Genet. 24: 355-362.

11. Maniatis, T., E.F. Fritsch, and J. Sambrook. 1982. Molecular cloning: A laboratory manual. Cold Spring Harbor Laboratory, Cold Spring Harbor, New York.

12. Darvasi, A. and M. Soller. 1992. Selective genotyping for determination of linkage between a marker locus and a quantitative trait locus. Theor. Appl. Genet. 85: 353-359.

13. Lander, E.S. and D. Botstein. 1989. Mapping Mendelian factors underlying quantitative traits using RFLP linkage maps. Genetics 121: 185-199.

14. Lebowitz, R., M. Soller, and J.S. Beckmannn. 1986. Trait based designs for determination of linkage between marker loci and quantitative trait loci. Theor. Appl. Genet. 72: 556-562.

Received January 28, 1994; accepted in revised form June 9, 1994. 


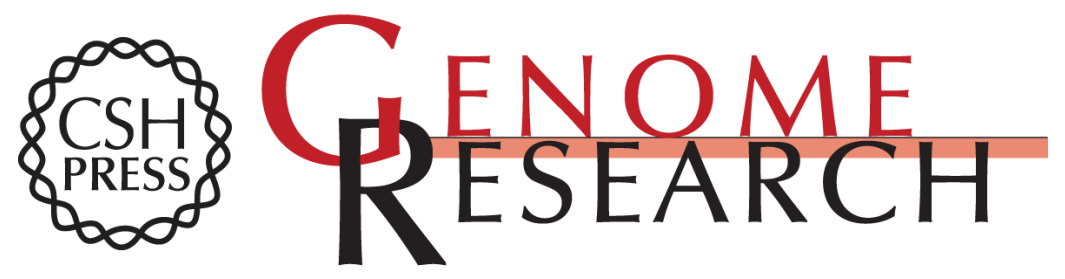

\section{Determining relative microsatellite allele frequencies in pooled DNA samples.}

H Khatib, A Darvasi, Y Plotski, et al.

Genome Res. 1994 4: 13-18

References This article cites 13 articles, 1 of which can be accessed free at: http://genome.cshlp.org/content/4/1/13.full.html\#ref-list-1

\section{License}

Email Alerting

Receive free email alerts when new articles cite this article - sign up in the box at the Service top right corner of the article or click here.

\section{Affordable, Accurate Sequencing.}

